\title{
Phase II Enzymes Inducer
}

National Cancer Institute

\section{Source}

National Cancer Institute. Phase II Enzymes Inducer. NCI Thesaurus. Code C54630.

Any natural or synthetic substance that enhances the activity of any phase II metabolic enzymes. Phase II detoxification enzymes, such as glutathione-S-transferase (GST), glucuronyl transferase, acyl transferase, or sulfotransferase, catalyze conjug ation reactions of xenobiotics or metabolites formed in phase I reactions. Conjug ation reactions greatly enhance polarity of xenobiotics or their metabolites, thereby facilitate their elimination from the body. Phase II conjugation reactions include glucuronidation, methylation, acetylation, and glutathione, sulfate and amino acid conjug ation. 